\title{
Analgetika med refusjon ved kroniske smerter
}

\begin{abstract}
BAKGRUNN Prevalensen av kronisk ikke-malign smerte i Norge er 24-30\%. Andelen av befolkningen som bruker opioider fast mot ikke-malign smerte er omtrent $1 \%$. Målet for vår studie var å undersøke hvor mange som fikk analgetika på blåresept med refusjonskode -71 (kronisk ikke-malign smerte) i 2009 og i 2010, hvilke analgetika som ble forskrevet og om forskrivningen var i tråd med nasjonale retningslinjer.
\end{abstract}

MATERIALE OG METODE Vi hentet pseudonymiserte data fra Reseptregisteret om alle som fikk medikamenter med refusjonskode -71 i 2009 og 2010. Dataene inneholder informasjon om medikament, dose, formulering, refusjonskode og tidspunkt for utlevering.

RESULTATER I 2010 fikk 90731 pasienter refusjon for uttak av medikamenter på indikasjonen kronisk ikke-malign smerte. Av disse fikk 6875 utlevert opioider, 33242 fikk paracetamol, 25865 ikke-steroide antiinflammatoriske midler (NSAID-midler), 20654 amitryptilin og 16507 gabapentin. Oksykodon var det hyppigst utleverte opioidet, fulgt av buprenorfin, tramadol og kodein-paracetamol. Av dem som fikk utlevert opioider, fikk 4047 (59\%) hovedsakelig lengevirkende opioider, 2631 (38\%) fikk samtidig benzodiazepiner og 2418 (35\%) fikk benzodiazepinliknende sovemidler.

KONKLUSJON Antallet som fikk analgetika og opioider på blåresept var lavt sammenliknet med andelen i befolkningen som har kronisk smerte og med andelen som har fast opioidbruk. $38 \%$ av dem som fikk opioider refundert, brukte også benzodiazepiner, noe som er i strid med offisielle norske retningslinjer.

Flere epidemiologiske studier viser at prevalensen av kronisk smerte i Norge er på omtrent $24-30 \%$ og at kun et fåtall av disse tilfellene oppgis å være kreftrelaterte (1-3). I en telefonintervjustudie fra Norge, 14 andre europeiske land og Israel oppga rundt halvparten (52\%) av dem med kronisk smerte at de for tiden brukte reseptbelagte analgetika (1). Omtrent en tredel fikk ingen behandling for sine smerter. Dette gjenspeiler at mange mestrer kroniske smerter uten farmakologisk behandling. Noen har imidlertid så sterke kroniske smerter at bruk av analgetika blir nødvendig. I Norge var det frem til 2008 bare pasienter med enkelte spesifikke diagnoser som artrose eller revmatoid artritt som fikk ikke-opioide smertestillende legemidler via blåreseptordningen. I samme periode var det på individuell basis mulig å søke særskilt om refusjon av utgifter til langvarig behandling med opioider.

Fra 2008 førte endringer i blåreseptordningen til at pasienter med kroniske smerter og betydelig nedsatt livskvalitet og funksjonsevne kunne få smertestillende legemidler gjennom blåreseptordningen med refusjonskode -71 (kronisk ikke-malign smerte). Denne ordningen gjelder for alle typer sterke, kroniske smerter og er ikke begrenset til enkelte diagnoser. For refusjon av opioider kreves det $i$ tillegg at faren for avhengighet er vurdert av spesialist eller sykehusavdeling som underordnet behovet for smertelindring (4).

Opioider som smertelindring er indisert for et mindretall av pasienter med kroniske ikke-maligne smerter der ikke-opioide anal- getika ikke gir tilstrekkelig lindring. Nasjonale retningslinjer anbefaler bruk av depotformuleringer når opioider er indisert $\mathrm{i}$ denne populasjonen $(5,6)$. Videre frarådes samtidig bruk av andre vanedannende legemidler og en kombinasjon av kort- og lengevirkende opioider $(5,6)$.

En nyere studie viser at andelen av befolkningen som bruker opioider fast over tid for ikke-maligne smerter var $1,08 \%$ ved utgangen av 2007 (7). Det er også kjent at pasienter med et høyt opioidbruk ofte får utlevert andre vanedannende legemidler i tillegg $(8,9)$. En studie fra Reseptregisteret viste at $50,5 \%$ av dem som brukte $>365$ definerte døgndoser (DDD) med kodein i 2005 også brukte $>100$ definerte døgndoser benzodiazepiner (8). En annen studie har vist at flertallet av dem som bruker høye doser opioider over tid, bruker kortvirkende opioider (9), noe som ikke er i tråd med de norske retningslinjene (5).

Forskningsspørsmålene for denne studien var:

- Hvor mange pasienter får analgetika med refusjonskode -71 ?

- Hvilke smertestillende legemidler forskrives med refusjonskode -71 ?

- Hvilke opioider, opioiddoser og opioidformuleringer blir forskrevet med refusjonskode -71 ?

- Hvilke andre smertestillende og vanedannende legemidler forskrives til pasienter som i tillegg får opioider med refusjonskode -71 ?

\author{
Line Pedersen \\ line.pedersen@ntnu.no \\ Anneli Borge Hansen \\ Kristian Svendsen \\ Nasjonal kompetansetjeneste for sammensatte \\ symptomlidelser \\ og \\ Forskningsgruppe smerte og palliasjon \\ Institutt for sirkulasjon og bildediagnostikk \\ Det medisinske fakultet \\ Norges teknisk-naturvitenskapelige universitet \\ Svetlana Skurtveit \\ Avdeling for legemiddelepidemiologi \\ Folkehelseinstituttet \\ og \\ Senter for rus og avhengighetsforskning \\ Universitetet i Oslo
}

\section{Petter C. Borchgrevink}

Olav Magnus S. Fredheim

Nasjonal kompetansetjeneste for sammensatte symptomlidelser

og

Forskningsgruppe smerte og palliasjon

Institutt for sirkulasjon og bildediagnostikk

Det medisinske fakultet

Norges teknisk-naturvitenskapelige universitet

og

Avdeling for smerte og sammensatte symptomlidelser

Klinikk for anestesi og akuttmedisin

St. Olavs hospital

ab Engelsk oversettelse på www.tidsskriftet.no

e-ramme 1, e-tab 4 og e-tab 5 finnes kun

i Tidsskriftets nettutgave.

> Se også side 2474

\section{HOVEDBUDSKAP}

Nærmere $2 \%$ av Norges befolkning fikk i 2010 analgetika på blåresept mot kronisk ikke-malign smerte

Dette utgjør en svært liten del av dem som i epidemiologiske studier angir kroniske smerter

I underkant av $8 \%$ av disse pasientene fikk forskrevet opioider, det tilsvarer $0,14 \%$ av befolkningen

Mange får utlevert kortvirkende opioider eller opioider samtidig med benzodiazepiner, noe som er i strid med norske retningslinjer 


\section{Materiale og metode Datakilde}

Fra 1.1. 2004 har alle norske apotek vært pålagt å rapportere data til Reseptregisteret om alle resepter som ekspederes. Informasjonen som registreres, er dato for utlevering, generisk navn, produktnavn, pakningsstørrelse, antall pakninger, ATC-kode (anatomisk terapeutisk kjemisk klassifikasjonssystem), mengde målt $\mathrm{i}$ definerte døgndoser og pris. En definert døgndose er den antatt gjennomsnittlige dosen per døgn ved bruk for preparatets hovedindikasjon hos voksne (10).

Pasientene identifiseres med et entydig kryptert nummer i stedet for personnummeret, slik at de kan følges pseudonymisert over flere år. Pasientenes alder, kjønn, bostedskommune, apotek og ev. refusjonskode i blåreseptordningen lagres. Forskrivere pseudonymiseres på samme måte med et kryptert identifikasjonsnummer, og informasjon om forskrivers spesialitet, kjønn og alder blir lagret (11).

\section{Studiepopulasjon}

I denne studien ble alle som fikk utlevert minst ett medikament med refusjonskode -71 i 2009 og/eller 2010 inkludert (tab 1). Studien er basert på data fra alle resepter som ble ekspedert til pasientene i 2009 og 2010.

\section{Analysestrategi}

Aldersstratifisert ettårs periodisk prevalens ble definert som antall pasienter og andel av Norges befolkning (12) som fikk utlevert minst én resept på et opioid med refusjonskode -71 (tab 2).

For analyser av komedisinering har vi av plasshensyn og på grunn av stabile mønstre for slik medisinering valgt kun å presentere data fra 2010 (tab 3). Komedisinering ble definert som andre legemidler utlevert minst én gang i tidsrommet mellom første og siste opioidresept med refusjon i 2010 og ble inndelt etter hvorvidt opioidbrukerne fikk hovedsakelig lengevirkende eller hovedsakelig kortvirkende opioider eller om de brukte både lengevirkende og kortvirkende. «Hovedsakelig bruk» av lengevirkende/kortvirkende formuleringer ble definert som at minst $90 \%$ av bruken målt $i$ definerte døgndoser var lengevirkende eller kortvirkende opioidformuleringer (tab 3). Totalt antall i tabell 3 er lavere enn totalt antall opioidbrukere i 2010, fordi det etter våre definisjoner for komedisinering var 431 pasienter som ikke fikk komedisinering.

Analyser av gjennomsnittlig døgndose av de hyppigst brukte opioidene i 2010 (e-tab 4) er basert på orale morfinekvivalenter (OMEQ) (13). OMEQ for ulike opioider er mer sammenliknbare med henblikk på ekvianalgetisk effekt enn DDD. Døgndoser av ulike opioider ble kalkulert som total mengde opioid delt på antall dager fra første til siste resept, med et tillegg av 30 dager (behandlingstiden). De som kun fikk én resept i behandlingstiden eller som fikk utlevert første og siste resept samme dag, inngikk ikke $i$ analyser av gjennomsnittlig døgndose. Dataene ble analysert i SPSS versjon 18 .

\section{Etikk}

Studien er basert på pseudonymiserte data fra Reseptregisteret, og det kreves derfor ikke behandling av regional komité for medisinsk og helsefaglig forskningsetikk eller personvernombudet.

\section{Resultater}

Totalt sett var det 854977 resepter som ble refundert med refusjonskode -71 i 2009 og 2010. Resepter som ble ekskludert på grunn av manglende entydig pasientidentifikasjon utgjorde $0,3 \%$, mens øvrige grunner for eksklusjon av resepter utgjorde ytterligere $0,3 \%$ (fig 1 ).

\section{Medikamenter refundert med refusjonskode -71}

I 2009 og 2010 fikk henholdsvis 77967 og 90 731 pasienter refundert minst én resept på et smertestillende medikament (tab 1). Hvert av årene fikk henholdsvis 7,2\% og 7,6\% av disse refundert minst én resept på et opioid. De smertestillende medikamentene som ble refundert hos flest pasienter i 2010 var paracetamol (33 242 pasienter) og ikke-steroide antiinflammatoriske midler (NSAID) (25 864 pasienter), fulgt av amitryptilin, gabapentin, pregabalin og opioider. Kvinneandelen varierte fra $55 \%$ til $72 \%$ for de ulike medikamentene, gjennomsnittsalderen fra 52 år til 62 år.

\section{Pasienter som mottar opioider}

med refusjsonskode -71

Henholdsvis 5634 og 6875 pasienter fikk opioider med refusjonskode -71 i 2009 og 2010 (tab 2). $66 \%$ var kvinner, og gjennomsnittlig alder for pasientene var 61 år begge årene. Prevalensen av opioidbruk med refusjon økte med økende alder.

Tabell 1 Oversikt over antall pasienter som fikk utlevert legemidler med smertelindrende effekt med refusjon etter refusjonskode - 71 i 2009 og 2010. Summen av antall utleveringer og prosentandeler for hvert medikament overstiger totalt antall pasienter (N) fordi noen fikk utlevert flere medikamenter

\begin{tabular}{|c|c|c|c|c|c|c|c|c|}
\hline & \multicolumn{4}{|c|}{$\begin{array}{c}2009 \\
N=77967\end{array}$} & \multicolumn{4}{|c|}{$\begin{array}{c}2010 \\
N=90731\end{array}$} \\
\hline & Antall & $(\%)$ & $\begin{array}{l}\text { Prosentandel } \\
\text { kvinner }\end{array}$ & $\begin{array}{l}\text { Alder (år) } \\
\text { Gjennomsnitt } \\
\text { (SD) }\end{array}$ & Antall & $(\%)$ & $\begin{array}{l}\text { Prosentandel } \\
\text { kvinner }\end{array}$ & $\begin{array}{c}\text { Alder (år) } \\
\text { Gjennomsnitt } \\
\text { (SD) }\end{array}$ \\
\hline Paracetamol & 25063 & (32) & 69 & 62 (17) & 33242 & (37) & 69 & 62 (17) \\
\hline NSAID-midler totalt ${ }^{1}$ & 23019 & (30) & 66 & $56(15)$ & 25864 & (29) & 66 & 55 (15) \\
\hline Amitryptillin & 16955 & (22) & 72 & $54(15)$ & 20654 & (23) & 72 & $54(15)$ \\
\hline Gabapentin & 15584 & (20) & 61 & $58(16)$ & 16507 & (18) & 61 & $58(16)$ \\
\hline Pregabalin & 9495 & (12) & 61 & $57(16)$ & 8112 & $(8,9)$ & 62 & $57(15)$ \\
\hline Karbamazepin & 3486 & $(4,5)$ & 55 & $61(17)$ & 3468 & $(3,8)$ & 56 & $61(17)$ \\
\hline Levomepromazin & 2620 & $(3,4)$ & 64 & $58(16)$ & 2956 & $(3,3)$ & 63 & $58(15)$ \\
\hline Duloksetin & 944 & $(1,2)$ & 65 & $52(15)$ & 1724 & $(1,9)$ & 67 & $53(15)$ \\
\hline Ikke-opioider totalt & 75643 & (97) & 66 & $59(17)$ & 87863 & (97) & 66 & $59(17)$ \\
\hline Opioider & 5634 & $(7,2)$ & 66 & $61(16)$ & 6875 & $(7,6)$ & 66 & $61(16)$ \\
\hline
\end{tabular}

Ikke-steroide antiinflammatoriske legemidler 


\section{De ulike opioidene}

Oksykodon var det hyppigst utleverte opioidet med refusjonskode -71 i 2010 , fulgt av buprenorfin og tramadol (e-tab 5). Totalt sett var det 5792 pasienter som fikk utlevert minst én resept av et lengevirkende opioid og 2556 som fikk minst én på et kortvirkende opioid med refusjon. Dette er høyere enn det totale antallet som fikk opioider refundert (6 875), fordi det var 1473 pasienter som fikk refundert både kort- og lengevirkende formuleringer.

\section{Opioidformuleringer og komedisinering}

Av pasientene som fikk opioider på blåresept fikk over $30 \%$ komedisinering med benzodiazepiner, mer enn $30 \%$ fikk benzodiazepinliknende sovemidler og mer enn halvparten fikk andre opioider utenfor refusjonsordningen (tab 3 ). Kun $21 \%$ av dem som fikk opioider fikk ikke samtidig andre vanedannende legemidler. Prevalensen av komedisinering med andre vanedannende legemidler var høyest hos pasienter som både fikk kort- og lengevirkende opioidformuleringer med refusjon.

\section{Opioiddoser}

Den prosentvise fordelingen av gjennomsnittlig døgndose er presentert i e-tabell 4. De fleste som fikk paracetamol-kodeinkombinasjoner fikk relativt lave døgndoser - $93 \%$ av disse fikk $<40 \mathrm{mg}$ OMEQ per dag og $59 \%<20 \mathrm{mg}$ OMEQ per dag (tilsvarende fire kodein-paracetamol-tabletter). Også for buprenorfin ble det utlevert overveiende lave og midlere doser $-10-100 \mathrm{mg}$ OMEQ per døgn til $93 \%$ av pasientene. Dosene til dem som fikk tramadol var noe høyere - 20-150 mg OMEQ per døgn til $93 \%$ av pasientene.

For de sterke opioidene morfin, oksykodon og fentanyl var mønstrene mindre entydige. Mens det særlig for morfin og fentanyl var høye andeler som fikk > $100 \mathrm{mg}$ OMEQ per døgn, ble det utlevert lavere doser til en stor andel av pasientene som fikk oksykodon.

\section{Diskusjon}

Hovedfunnene i denne studien er at omtrent $2 \%$ av befolkningen får smertestillende legemidler med refusjon på grunn av kronisk ikke-malign smerte og at $0,14 \%$ av befolkningen får opioider gjennom denne ordningen. Dette er lave andeler med tanke på at $24-30 \%$ av den norske befolkningen rapporterer kronisk smerte $(1-3)$ og at i overkant av $1 \%$ av befolkningen bruker opioider fast over tid for andre indikasjoner enn palliativ behandling (7).

En stor andel av dem som får opioider på blåresept har fått både kortvirkende og lengevirkende opioidformuleringer og/eller benzodiazepiner. Dette er i strid med nasjonale retningslinjer $(5,6)$. Det var flere som mottok smertestillende med refusjon på grunn av ikke-maligne smerter i 2010 enn i 2009, men mønstrene synes å være stabile. Økningen kan skyldes økende oppmerksomhet rundt ordningen og at det for opioidene var begrenset kapasitet for spesialistvurderinger $\mathrm{da}$ refusjonspunktet ble innført.

Denne studien viser at i 2009/2010 fikk under $10 \%$ av alle som angir kronisk smerte refusjon på analgetika etter den nye forskriften. Dette er en betydelig lavere andel enn den man ut fra tidligere studier antar bruker analgetika over tid. I en telefonintervjustudie utført i Norge samt en rekke andre land oppga $52 \%$ av dem med kroniske smerter at de «for tiden brukte reseptbelagte analgetika» (1). En litt eldre norsk studie viste at $43 \%$ av den delen av befolkningen som rapporterte kronisk smerte, brukte analgetika (3). I en amerikansk telefonintervjustudie rapporterte $4,9 \%$ av den generelle befolkningen å ha brukt opioider minst fem dager i uken de siste fire ukene (14).

Mens man har svært usikre data om hvor mange som bruker ikke-opioide analgetika og koanalgetika på fast basis, er det nylig kommet sikrere data for hvor mange som bruker opioider fast. Data fra det norske Reseptregisteret har vist at $\mathrm{i}$ overkant av $1 \%$ av befolkningen får opioider fast på grunn av andre indikasjoner enn palliativ behandling (7).

Antallet som får opioider med refusjon for kronisk ikke-malign smerte, utgjør i vårt materiale $0,14 \%$ av befolkningen. Denne forskjellen kan enten tolkes som at det overveiende flertallet av pasienter som mottar opioider for kronisk ikke-malign smerte ikke får utgiftsdekningen de har rett til, eller at et høyt antall pasienter mottar opioider fast uten å oppfylle vilkårene for refusjon av
Tabell 2 Pasienter som har fått refundert minst én resept på et opioid med refusjon etter refusjonskode -71 i 2009 og 2010 . For hver aldersgruppe er antall mottakere og prosentandel av landets befolkning angitt. Befolkningstall for 2009 og 2010 er innhentet fra Statistisk sentralbyrå og var henholdsvis 4799252 og 4858199 mennesker

\begin{tabular}{|c|c|c|c|c|}
\hline \multirow{2}{*}{$\begin{array}{l}\text { Alders- } \\
\text { gruppe } \\
\text { (år) }\end{array}$} & \multicolumn{2}{|c|}{2009} & \multicolumn{2}{|c|}{2010} \\
\hline & Antall & (\%) & Antall & (\%) \\
\hline$<40$ & 515 & $(0,02)$ & 573 & $(0,02)$ \\
\hline $40-49$ & 1050 & $(0,15)$ & 1244 & $(0,18)$ \\
\hline $50-59$ & 1237 & $(0,20)$ & 1499 & $(0,24)$ \\
\hline $60-69$ & 1113 & $(0,23)$ & 1391 & $(0,28)$ \\
\hline $70-79$ & 844 & $(0,29)$ & 974 & $(0,34)$ \\
\hline$>80$ & 875 & $(0,40)$ & 1194 & $(0,54)$ \\
\hline Totalt & 5634 & $(0,12)$ & 6875 & $(0,14)$ \\
\hline
\end{tabular}

utgifter til opioider. Den første forklaringen ville innebære at mange pasienter har en urimelig og unødvendig økonomisk byrde i tillegg til sin smertetilstand, den siste ville innebære et betydelig samfunnsproblem der mange pasienter bruker opioider fast uten god medisinsk indikasjon. Siden man ikke har tilgang på kliniske data om pasientene $\mathrm{i}$ Reseptregisteret, er det ut fra dataene i denne studien ikke mulig å avgjøre hvilken forklaring som er korrekt.

Tabell 3 Oversikt over antall pasienter som fikk refundert opioider med refusjonskode-71 i løpet av 2010 og som i tillegg fikk utlevert minst ett av legemidlene nedenfor i tidsrommet mellom første og siste opioidresept. Stratifisert etter hvorvidt pasientene har fått utlevert hovedsakelig kortvirkende opioider, hovedsakelig lengevirkende opioider eller begge

\begin{tabular}{|c|c|c|c|c|c|c|}
\hline & \multicolumn{2}{|c|}{$\begin{array}{l}\text { Hovedsakelig } \\
\text { lengevirkende } \\
\text { ( } n=4 \text { 047) }\end{array}$} & \multicolumn{2}{|c|}{$\begin{array}{l}\text { Hovedsakelig } \\
\text { kortvirkende } \\
\text { (n=1 051) }\end{array}$} & \multicolumn{2}{|c|}{$\begin{array}{c}\text { Kortvirkende } \\
\text { og lengevirkende } \\
\text { ( } n=1346)\end{array}$} \\
\hline & Antall & $(\%)$ & Antall & $(\%)$ & Antall & $(\%)$ \\
\hline Andre opioider uten refusjon & 2350 & (58) & 580 & (55) & 949 & (70) \\
\hline Paracetamol & 1965 & (49) & 364 & (35) & 684 & $(51)$ \\
\hline Benzodiazepiner & 1579 & (39) & 366 & (35) & 686 & (51) \\
\hline Z-hypnotika & 1376 & (34) & 490 & $(47)$ & 552 & (41) \\
\hline NSAID-midler & 1318 & (33) & 317 & (30) & 468 & (35) \\
\hline Gabapentin & 537 & (13) & 124 & $(12)$ & 242 & (18) \\
\hline Pregabalin & 450 & (11) & 77 & $(7,3)$ & 158 & $(12)$ \\
\hline Amitryptilin & 445 & (11) & 96 & $(9,1)$ & 166 & (12) \\
\hline Levomepromazin & 75 & $(1,9)$ & 17 & $(1,6)$ & 60 & $(4,5)$ \\
\hline Karbamazepin & 36 & $(0,9)$ & 7 & $(0,7)$ & 18 & $(1,3)$ \\
\hline Duloksetin & 35 & $(0,9)$ & 12 & $(1,1)$ & 23 & $(1,7)$ \\
\hline
\end{tabular}




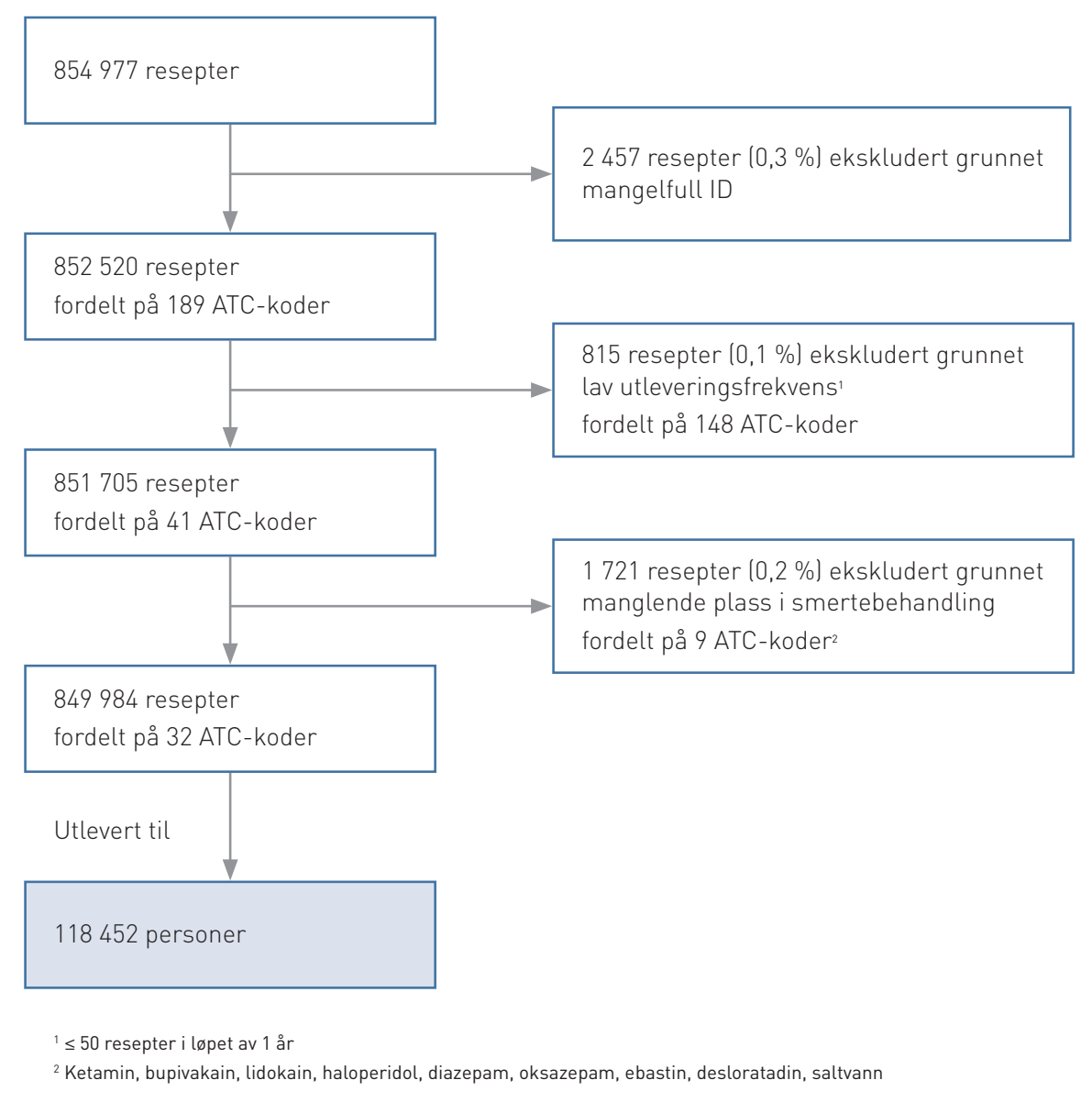

Figur 1 Antall resepter som ble ekskludert under analysene samt årsak til eksklusjonene

Det er imidlertid grunn til å anta at det finnes få gode indikasjoner for langvarig behandling med opioider der behandlingen ikke oppfyller kravene til refusjon med refusjonskode -71. Den enkelte lege bør derfor nøye vurdere om slike pasienter enten bør motta opioider med refusjon etter blåreseptordningen eller om opioidbehandlingen bør avsluttes. For pasienter i livets sluttfase finnes det andre refusjonsordninger, og slike forskrivninger ble ikke inkludert i denne studien. Tidligere har antallet som får opioider med refusjon for palliativ behandling vært 12 000-13000 personer/år (9).

Ikke-opioide analgetika skal være førstelinjebehandling av kroniske ikke-maligne smerter. Det gjenspeiles i denne studien, der omtrent en tredel av pasientene som får refundert analgetika får paracetamol og en tredel får refundert NSAID-midler. Paracetamol er relativt trygt i langtidsbruk, mens langvarig bruk av NSAID-midler kan gi dels alvorlige bivirkninger, blant annet $\mathrm{i}$ form av gastrointestinale blødninger, særlig hos eldre og hos pasienter med hjerte-, lunge- eller nyresykdom. I denne studien fant vi at mange har fătt refundert paracetamol og ikke-steroide antiinflammatoriske midler i tillegg til opioider. Dette vil kunne gi en opioidsparende effekt, men må veies nøye mot faren for bivirkninger av NSAID-midlene.

Forskrivningsmønsteret gjenspeiler også at amitryptilin er førstelinjepreparatet ved nevropatisk smerte. En høyere andel med refusjon for gabapentin sammenliknet med pregabalin skyldes trolig kravet om at det rimeligere preparatet gabapentin må prøves først, mens det for pregabalin gis refusjon etter individuell søknad. Antallet som mottar amitryptilin, gabapentin eller pregabalin uten å få opioider er vesentlig høyere enn antallet som mottar både opioider og et av disse legemidlene. Det tyder på at opioider brukes som supplerende behandling hos kun en forholdsvis liten andel av pasientene med nevropatisk smerte.

For duloksetin og pregabalin kan endringer i refusjonsreglene ha påvirket forskrivningsmønsteret mellom 2009 og 2010. I de tilfellene der refusjon er knyttet til spesifikke diagnoser, kan man spekulere i om det er en tilbøyelighet til å sette diagnoser som kvalifiserer til refusjon. Pasienter som mottar midlere eller høyere doser av svake opioider bør i henhold til retningslinjene konverteres til en depotformulering av et sterkt og lengevirkende opioid. Et tilleggsmoment i den sammenheng er at de som bruker høye doser tramadol eller kombinerer tramadol med enkelte andre medikamenter, har risiko for å utvikle serotonergt syndrom.

At forekomsten av opioidutlevering øker med økende alder, stemmer godt overens med at prevalensen av smertefulle tilstander også er økt hos eldre $(1,2)$. Opioider kan ha god effekt hos eldre, men bivirkninger som falltendens og nedsatt kognitiv funksjon gjør at effekt og bivirkninger må evalueres nøye.

Av dem som får refundert opioider på blåresept, er det fire ganger så mange som hovedsakelig får lengevirkende opioider enn antallet som hovedsakelig får kortvirkende. Dette tyder på at retningslinjene overveiende blir forsøkt fulgt på dette punktet. Derimot er det bekymringsverdig og tydelig i strid med retningslinjene at det er $>30 \%$ som komedisinerer med benzodiazepiner og $>50 \%$ som komedisinerer med andre opioider utenfor refusjonsordningen.

I den generelle befolkningen mottar omtrent $10 \%$ opioider i løpet av et år, i hovedsak i små mengder (9) og trolig på grunn av akutte smerter. Man ville forvente at det også blant dem som bruker opioider fast opptrer akutte tilstander med indikasjon for kortvarig $ø$ kning i opioiddosen. Imidlertid tyder den svært høye andelen pasienter som i løpet av året mottar opioider både med og uten refusjon på at mange som får lengevirkende opioider med refusjon, bruker et kortvirkende preparat i tillegg, uten at dette skyldes akutte skader eller liknende. Det er advart mot slik bruk i retningslinjene, den kan indikere fare for utvikling av eller etablert problematisk opioidbruk. Prevalensen av komedisinering med andre vanedannende legemidler er særlig høy i gruppen som får refundert større mengder av både kort- og lengevirkende opioider, og man kan anta at både forekomsten av og risikoen for å utvikle problematisk opioidbruk derfor er høyere her enn blant de øvrige pasientene i studiepopulasjonen.

Styrken ved studier basert på Reseptregisteret er at datamaterialet omfatter alle resepter som er ekspedert i Norge i studieperioden og at man har data på individnivå som ikke er basert på egenrapportering. Svakheten med slike studier er at man ikke kan vite når eller om medikamentet blir brukt av mottakeren. En annen ulempe er at man heller ikke har tilgang til individuelle data for medikamentbruk i sykehus og sykehjem. Særlig for eldre og kronisk syke blir det derfor en underestimering av både medikamentbruk og medikamentdoser.

En svakhet med denne studien er at man ikke kjenner til om de som i løpet av studieperioden har fått utlevert ulike opioider og opioidformuleringer, bruker de ulike preparatene samtidig, om de har gjennomført et bytte av behandling eller om de veksler mellom behandlinger. Rekkefølgen reseptene er ekspedert i, gjenspeiler ikke nødvendigvis den rekkefølgen medikamentene er brukt $i$.

\section{Konklusjon}

Denne studien viser at pasienter som får analgetika med refusjon på indikasjonen kronisk, ikke-malign smerte, i hovedsak får ikke-opioide analgetika. Siden antallet som mottar refusjon etter blåreseptordningen er lavt sammenliknet med den store andelen av 
befolkningen som har kronisk ikke-malign smerte, er det grunn til å anta at mange pasienter selv bærer kostnadene knyttet til bruk av smertestillende legemidler. Pasienter med god indikasjon for fast bruk av både ikke-opioide analgetika og opioider bør i tråd med regelverket få disse legemidlene innenfor blåreseptordningen.

Hos dem som ikke oppfyller kravene til refusjon, vil det i mange tilfeller være riktig å avslutte langvarig behandling med opioider. Kombinasjonsbruk av ulike opioider/formuleringer og/eller samtidig bruk av benzodiazepiner er hyppig forekommende og i strid med retningslinjene. Dette innebærer trolig $ø$ kt risiko for problematisk opioidbruk.

\section{Line Pedersen (f. 1982)}

er cand.med., tidligere forskerlinjestudent og nå doktorgradsstipendiat ved Norges teknisk-naturvitenskapelige universitet. Forfatter har fylt ut ICMJE-skjemaet og oppgir ingen interessekonflikter.

\section{Anneli Borge Hansen (f. 1982)}

er cand.med. og doktorgradsstipendiat ved Norges teknisk-naturvitenskapelige universitet. Forfatter har fylt ut ICMJE-skjemaet og oppgir ingen interessekonflikter.

\section{Kristian Svendsen (f. 1982)}

er master i farmasi og ph.d. i samfunnsmedisin (legemiddeldepidemiologi).

Forfatter har fylt ut ICMJE-skjemaet og oppgir ingen interessekonflikter.

\section{Svetlana Skurtveit (f. 1962)}

er seniorforsker og professor.

Forfatter har fylt ut ICMJE-skjemaet og oppgir

ingen interessekonflikter.

\section{Petter C. Borchgrevink (f. 1952)}

er overlege og spesialist i anestesiologi, leder av Nasjonal kompetansesetjeneste for sammensatte symptomlidelser og professor ved Forskningsgruppe smerte og palliasjon ved Norges teknisk-naturvitenskapelige universitet. Forfatter har fylt ut ICMJE-skjemaet og oppgir ingen interessekonflikter.

\section{Olav Magnus S. Fredheim (f. 1979)}

er ph.d. i smertemedisin, lege i spesialisering i anestesiologi og forsker.

Forfatter har fylt ut ICMJE-skjemaet og oppgir ingen interessekonflikter.

\section{Litteratur}

1. Breivik H, Collett B, Ventafridda V et al. Survey of chronic pain in Europe: prevalence, impact on daily life, and treatment. Eur J Pain 2006; 10: 287-333.

2. Landmark T, Romundstad P, Borchgrevink PC et al. Associations between recreational exercise and chronic pain in the general population: evidence from the HUNT 3 study. Pain 2011; 152: 2241-7.

3. Rustøen T, Wahl AK, Hanestad BR et al. Prevalence and characteristics of chronic pain in the general Norwegian population. Eur J Pain 2004 8: 555-65.

4. Folketrygdloven § 5-14. Legemidler, næringsmidler og medisinsk forbruksmateriell. 2011. www.lovdata.no/for/sf/ho/xo-20070628-0814.htm (29.8.2012).

5. Terapianbefaling: Bruk av opioider ved behandling av langvarige, non-maligne smertetilstander - en oppdatering. Oslo: Statens legemiddelverk, 2008

6. Bell RF, Bjørner T, Forseth KØ et al. Retningslinjer for smertelindring. Oslo: Den norske legeforening 2009

7. Svendsen K, Skurtveit S, Romundstad P et al. Differential patterns of opioid use: Defining persistent opioid use in a prescription database. Eur J Pain 2011. E-publisert 19.12.

8. Fredheim OM, Skurtveit S, Moroz A et al. Prescription pattern of codeine for non-malignant pain: a pharmacoepidemiological study from the Norwegian Prescription Database. Acta Anaesthesiol Scand 2009; 53: 627-33.

9. Fredheim OM, Skurtveit S, Breivik H et al. Increasing use of opioids from 2004 to 2007 - pharmacoepidemiological data from a complete national prescription database in Norway. Eur J Pain 2010 14: $289-94$

10. International language for drug utilization research. www.whocc.no/ (12.10.2011)

11. Furu K, Wettermark B, Andersen M et al. The Nordic countries as a cohort for pharmacoepidemiological research. Basic Clin Pharmacol Toxicol 2010: 106: 86-94

12. Statistisk sentralbyrå. www.ssb.no (12.10.2011)

13. Svendsen K, Borchgrevink PC, Fredheim 0 et al. Choosing the unit of measurement counts: the use of oral morphine equivalents in studies of opioid consumption is a useful addition to defined daily doses. Palliat Med 2011; 25: 725-32.

14. Parsells Kelly J, Cook SF, Kaufman DW et al. Prevalence and characteristics of opioid use in the US adult population. Pain 2008; 138: 507-13.

Mottatt 2.12. 2011, første revisjon innsendt 1.3. 2012, godkjent 29.8. 2012. Medisinsk redaktør Merete Kile Holtermann. 